\title{
GPS 高程拟合代替四等水准测量精度探析
}

\author{
唐晓伟 \\ 中交第一公路工程局集团有限公司，陕西 西安 710061
}

[摘要] 随着 GPS 空间定位技术的不断发展，其应用领域愈发广泛，对其他常规测量技术也产生了巨大的冲击，其中也包括水 准测量方法。基于此，文章对 GPS 高程拟合代替四等水准测量的精度进行探究，分别从测高原理、大地水准面高的计算及 GPS 水准误差以及 GPS 高程拟合测量实例等方面对其展开细致地研究。

[关键词]GPS; 高程拟合; 四等水准测量

DOI: $10.33142 /$ ec.v3i8.2379

中图分类号: P224.1;P228.4

文献标识码：A

\section{Discussion on Accuracy of GPS Height Fitting Instead of Fourth Order Leveling}

TANG Xiaowei

China Communications First Highway Engineering Bureau Group Co., Ltd., Xi'an, Shaanxi, 710061, China

\begin{abstract}
With the continuous development of GPS spatial positioning technology, its application field is more and more extensive, which also has a huge impact on other conventional survey technology, including leveling method. Based on this, this paper explores the accuracy of GPS Height Fitting instead of fourth-class leveling, and makes a detailed study on the principle of height measurement, the calculation of geoid height, GPS leveling error and GPS height fitting survey examples.
\end{abstract}

Keywords: GPS; elevation fitting; fourth grade leveling

\section{引言}

在传统的测绘工程中, 大多采用的是几何水准测量方法搭建高精度的水准网进而实现高程控制, 而 GPS 高程测量 却因可靠性没有保障而常常被人忽视。随着北斗卫星的加入, GPS 技术已经在大范围高精度测量控制网、城市控制网、 工程控制网以及测绘控制网中起着非常重要的作用。在公路控制测量中通常采用静态相对定位技术。该技术全天候、 无需通视, 可构成较强的图形结构等特点, 显示了常规测量无可比拟的优越性, 大大减轻了劳动强度, 提高了工作效 率和测量精度。现阶段随着 GPS 技术的不断发展及区域性厘米级似大地水准面的建成为 GPS 测高提供了有效地技术支 持, 以在大大提升 GPS 测量精度的同时代替原有的测量方法。

\section{1 测高原理}

\section{1 水准测量原理}

水准测量的原理是通过水准仪和水准尺对地面点间的高差进行测算, 该过程中采用逐站传递的方式, 有效对各种 影响水准测量的误差加以改正, 进而在高等级水准点的控制过程中实现对未知点高程的测算。但这种方法在实施的过 程中，容易受到地形因素的限制，进而有着观测视距不足、劳动强度较大以及工作效率低下等弊端。

\subsection{GPS 高程测量原理}

采用 GPS 测量方法进行大地高测算时是以 WGS - 84 参考栯球面为基准的，而我国实际采用的通常是以似大地水准 面为起算面的正常高, 所以需要对 GPS 测量所得出的大地高进行正常高的转换, 二者之间存在一定的高程异常值差异, 而二者的转换公式为: $H=h+\zeta$, 其中 $H$ 表示大地高, $h$ 为正常高, 而 $\zeta$ 则为高程异常值, 也可以称之为大地水准面差距。

现阶段, 各 GPS 点上的高程异常值并不能直接获得所以在大地高精确转换正常高的过程中还存在着一定困难, 因 此 GPS 高程异常的测算也就成为了 GPS 高程转换中的关键环节。地区地层的密度以及地形走向都会对高程异常值产生 直接的影响, 而想得出正常高的精确值就需要先进行高程异常值 $\zeta$ 的测算。目前, 高程异常值 $\zeta$ 的测算方法主要有以 下几种: 首先是参照 EGM96 模型以及 OSU91A 模型等全球高程异常模型, 或者也可以查询国家高程异常值图, 但这两种 方法的精度都在分米到米级之间, 距离测算的实际生产需求差距较大; 其次是参照地区似大地水准面精化模型, 通常 情况下该模型呈现出的各地区似大地水准面精化分辨率较高, 城市、平原地区精度可以达到 $\pm 5.0 \mathrm{~cm}$ 以内, 而山区、高 山地区则可以达到 $\pm 15.0 \mathrm{~cm}$ 以内; 最后是采用高程拟合方法, 该方法是现阶段较为常见且效率较高的方法, 其具体的 
操作方法是先对测量区域内的点位进行 GPS 测量从而得出大地高, 再通过水准联测得出正常高, 进而利用水准重合点 得出大地高和正常高的关系, 测算出离散点上的高程异常值, 在得到局部区域的似大地水准面以后就可以得出未知点 上的高程异常值。

\section{2 大地水准面高的计算及 GPS 水准误差}

\section{1 大地水准面高的计算方法}

现阶段求取大地水准面高的计算方法十分多样, 计算高程异常 $\zeta$ 的方法也有很多种, 其中主要包括天文大地水准 方法、地球重力场模型以及数值拟合法等。而数值拟合法作为其中求解大地水准面高最常用的方法, 主要包括绘等值 线图法、解析内插法以及曲面拟合法等。

\section{2 GPS 水准误差}

2.2.1 几何水准联测误差

在进行 GPS 水准的相关操作过程中, 通常情况下会进行四等几何水准联测, 进而也会造成待定点正常高误差的出现, 在这样的情况下, 应采用以下公式进行计算: $\mathrm{m}_{1}= \pm 10 \sqrt{\mathrm{L}}(\mathrm{mn})$, 其中 $\mathrm{L}$ 表示待求点和已知点之间的距离, 并以 $\mathrm{km}$ 作为 基本单位。

\subsubsection{GPS 测定大地高的误差}

一般情况下 GPS 测定大地高所存在的误差会大于相邻两点之间距离测算过程存在的误差, 且通常为 2 倍的关系。 现阶段, 单频接收机只能进行 $\mathrm{C} / \mathrm{A}$ 码的接收, 而双频接收机除了 $\mathrm{C} / \mathrm{A}$ 码以外还可以接收 L $2 \mathrm{C}$ 码, 进而相较于单频接收 机可以有效减少电离层的误差, 相应的精度也会更高。

\subsection{3 坐标转换误差}

GPS 定位中的高程坐标分量是以 WGS - 84 参考椭球的大地高 H 作为基准, 而我国通常使用的是正常高系统, 因此 在进行计算时需要将二者加以转换。因此在进行转换的过程中需要加强对两种不同坐标系之间粗球以及平移参数差别 的考量, 进而有效提升 GPS 水准测算的精准程度 ${ }^{[1]}$ 。

\subsection{4 拟合计算误差}

通过以往的实践经验可以得出, 在开展拟合计算的过程中即使处于同一个测量区, 而得出的结果也会受到已知点 数量以及分布不同等因素的影响, 进而造成拟合精度的不相同。面对这样的情况, 在实际开展测量工作的过程中, 必 须在对现场实际情况进行分析与考量之后开展工作，进而有效提升拟合计算的精确度。

\section{GPS 高程拟合测量实例分析}

\section{1 水准测量与 GPS 高程测量}

以某开发区路网控制测量项目为例, 在进行 GPS 测量的过程中要进行 D 级 GPS 控制点的布设, 其分布为每隔大约 $1 \mathrm{~km}$ 布设一对, 一共需要布设 29 点, 同时还有 3 个联测 C 级 GPS 控制点。本次水准测量采用的设备为 S05 级电子水准 仪以及配套的铟瓦水准尺, 在此过程中采用四等水准的要求对该区域内 8 个一等 GPS 控制水准点进行了联测, 并在测 量的过程中严格遵循了 (GB / T12898--2009) 《国家三、四等水准测量规范》中的规定 ${ }^{[2]}$ 。

\section{2 高程拟合实施}

在实施高程拟合时主要采用的是曲面拟合的方法, 进而在 GPS 点布设形成一定的区域面积以后, 就采用数学曲面 拟合的方法对待定点正常高进行测算。其中的测算原理是参考该区域内已知点位的平面坐标和 $\zeta$ (高程异常) 值, 通 过数字拟合测算出该区域的似大地水准面, 进而内插待求点 $\zeta$ 得出其正常高的数值。将相应的原理落实到实际步骤中 则为现在一定的区域面中对 GPS 控制点展开均匀有效布设, 再根据当前已知的条件包括控制点大地坐标 (B, L)、平面 坐标 $(x, y)$ 以及高程异常 $(\zeta)$ 值采用数学曲面拟合法对似大地水准面进行测算, 再内插计算出各个点位的高程异常值, 进而转换为正常高。

\section{3 绘制高程异常等值线图}

绘制高程异常等值线图是一个简单高效的计算高程异常的方法, 将该方法运用于相对平坦地形中的测算时可以有 效达到较高的精度级别。绘制等值线图的基本原理是通过绘图的方法来内插得到待求的高程异常值, 其过程中的具体 操作步骤为先用 GPS 在该区域内测定一些均匀分布控制点的大地高, 再借助水准测量的方法求出这部分点的水准高, 将 $H=h+\zeta$ 这一公式引入其中的测算过程, 进而得出这部分点位的高程异常值, 再在图纸内参照已知点的平面坐标选取 
一定的比例尺, 同时对相对应的已知点高程异常值在上面标注出来, 这样就可以在得知等高距的基础上实现高程异常 值等值线图的绘制。其后就可以采用内插法计算出待测点的高程异常值, 进而转换为待测点的正常高。通过测算得出 本次测量的结果，并借助 Cass2008 生成高程异常等值线图，进而得出高程异常值。

\section{4 精度分析与比较}

在测量完成以后就要进行精度分析与比较, 采用的方法为在该测量区域内选取 5 个代表性较强的控制点, 再把这 5 个控制点的拟合计算高程值与四等水准测量结果加以比较, 其误差最多只有 $0.01 \mathrm{~m}$, 进而有效满足了《卫星定位城市测 量技术规范》中所规定的相关要求。同时也可以得出生成的高程异常等值线图与实际的情况较为符合，因此 GPS 拟合 高程可以有效代替原有的四等水准测量方法。具体的对比结果如表 1 所示:

表 1 四等水准高程与 GPS 拟合高程测量结果对比表

\begin{tabular}{c|c|c|c|c|c}
\hline 点号 & 大地高 $\mathrm{H} / \mathrm{m}$ & 内插值 $\zeta_{\mathrm{i}} / \mathrm{m}$ & GPS 拟合高程 $\mathrm{h} / \mathrm{m}$ & 四等水准高程 $\mathrm{H} / \mathrm{m}$ & 差值 $/ \mathrm{m}$ \\
\hline W23B015 & 40.575 & 10.342 & 21.233 & 21.223 & 0.010 \\
\hline W23B016 & 41.448 & 10.453 & 21.995 & 22.004 & -0.009 \\
\hline W23B018 & 40.506 & 10.512 & 20.994 & 20.987 & 0.007 \\
\hline W23B021 & 40.525 & 10.413 & 21.112 & 21.108 & 0.004 \\
\hline W23B025 & 42.667 & 10.329 & 23.338 & 23.345 & -0.007 \\
\hline
\end{tabular}

\section{4 总结}

根据本人的工作实践, 得出以下几点经验:

（1）在小范围内, 地势起伏不是很大的地区, 选择合适的数学模型, GPS 高程拟合可以达到四等水准测量的精度;

(2) 参与高程拟合的高等级控制点要尽量反映高程异常的变化趋势;

(3) 同一种拟合方法, 起算点数量越多、分布越均匀, 则拟合精度越高, GPS 高程拟合测区比较大的情况下, 采 用分区拟合较为合理。

（4）已知点的选取对拟合的精度影响很大，因此已知点应该尽量选取均匀点位; 而且已知点要包围整个测区。

(5) 为了提高拟合精度, 在进行 GPS 高程拟合时, 可先用检验点检验模型的拟合效果, 在检验合格后, 再让检验 点作为拟合点参与拟合, 这样可以提高拟合的精度。

综上所述, GPS 水准测量方法相较于传统的几何水准测量具备费用低、效率高的优势, 进而可以在大范围的区域内 形成高程数据加密。在平坦与丘陵地区进行测算时, 可以采用高程拟合模型求出高程异常值, 进而利用 GPS 测量转换 正常高。同时代替了几何水准测量，在减少人力物力投入的基础上提高了工作效率。

\section{[参考文献]}

[1]徐方兵. GPS 拟合高程代替等级水准测量的应用研究 [J]. 资源信息与工程, 2019,34(1): 145-146.

[2]陈水航. GPS 高程拟合代替四等水准测量精度分析与探讨 [J]. 经纬天地, 2018(2): 51-54.

作者简介: 唐晓伟 (1987.1-), 男, 毕业院校: 长沙理工大学, 所学专业: 交通土建, 单位: 中交第一公路工程局集 团有限公司，中级职称。 